\title{
A TRAGÉDIA MACBETH REESCRITA PARA O PÚBLICO INFANTIL POR CHARLES LAMB
}

\section{MACBETH'S TRAGEDY REWRITTEN FOR CHILDREN BY CHARLES LAMB}

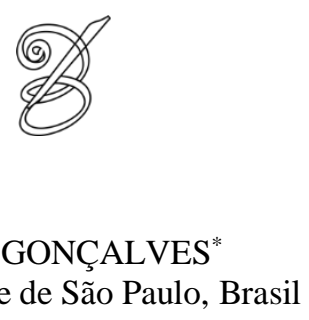

Resumo: Este artigo tem como propósito refletir sobre algumas questões envolvidas na reescrita de peças de William Shakespeare para o público infantil, focalizando a narrativa Macbeth, publicada em Tales from Shakespear. Designed for the use of young persons (1807) pelos irmãos Charles e Mary Lamb. Para o embasamento teórico, são primordialmente utilizadas as teorias dos Estudos da Tradução, com as concepções de André Lefevere e a teoria dos polissistemas de Itamar Even-Zohar. Inicialmente, são feitas breves considerações sobre a biografia dos autores e sobre a contextualização da obra no sistema literário infantil. Na sequência, apresentamos as características da fonte textual que podem ser consideradas questões complexas em uma adaptação para crianças. Então, a análise comparativa demonstra as particularidades da narrativa de Charles Lamb que a transformam em um novo original, que acaba tornando-se a verdadeira história de Shakespeare para os leitores que não conhecem a tragédia Macbeth.

Palavras-chave: Literatura Infantil. Tradução Literária. Adaptação. William Shakespeare. Charles Lamb.

Abstract: This paper aims to reflect on some questions regarding William Shakespeare's theatre plays rewritten for children, focusing on the Macbeth narrative, which was published in Tales from Shakespear. Designed for the use of young persons (1807) by the siblings Charles and Mary Lamb. The research was conducted in light of the concepts of Translation Studies, such as the conception of rewriting by André Lefevere and the Polysystems Theory by Itamar Even-Zohar. First of all, we make some considerations concerning the biography of the authors as well as the publication's contextualization into the children's literary system. Afterwards, we present some features of the textual source that can be considered complex issues in an adaptation for children. Then, the comparative analysis demonstrates which singularities of Charles Lamb's narrative transform it into a new original, that becomes the Shakespeare's true story for the readers who are not familiar with the tragedy of Macbeth.

Keywords: Children's Literature. Literary Translation. Adaptation. William Shakespeare. Charles Lamb.

RECEBIDO EM: 14 de fevereiro de 2019

ACEITO EM: 04 de maio de 2019

PUBLICADO EM: julho 2019 


\section{Introdução}

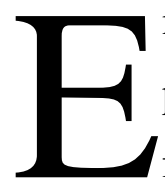

m sua obra Literatura Infantil: teoria, análise, didática, Nelly Novaes Coelho (2011,

p. 27) salienta que "a literatura infantil é, antes de tudo, literatura; ou melhor, é arte:

fenômeno de criatividade que representa o mundo, o homem, a vida, através da palavra. Funde os sonhos e a vida prática, o imaginário e o real, os ideais e sua possível/impossível realização". Para ela, a literatura visa proporcionar prazer estético, do mesmo modo que busca despertar ou modificar a consciência crítica de seu receptor. A literatura traz em sua essência, desde seu início, essa função de atuar sobre as mentalidades, podendo intervir nos desejos e ações dos homens, assim modificando ou engrandecendo suas experiências existenciais. O âmago da literatura designada às crianças é o mesmo, diferenciando-se apenas pela natureza do seu público leitor, que precisa de matéria adequada ao seu entendimento e curiosidade. Ademais, cada época compreende e produz literatura de uma maneira singular, própria, e o conhecimento da literatura destinada às crianças permite a compreensão dos valores nos quais uma sociedade foi fundamentada (COELHO, 2011).

As origens da chamada Literatura Infantil remontam ao século XVIII, quando alguns textos escritos em sua origem para o público adulto, como contos de fadas, foram adaptados com a finalidade de educar crianças, transmitindo, por intermédio de seus enredos, valores morais. Naquele tempo, os públicos leitores não eram particularizados por faixa etária ou etapa de amadurecimento psicológico, no entanto, havia uma explícita separação em função das camadas sociais. Orientadas pelos pais e preceptores, as crianças das altas classes sociais liam os cânones da literatura, como Fábulas (1668-1694), de Jean de La Fontaine (1621-1695), As Mil e Uma Noites (1704), traduzido do árabe para o francês por Antoine Galland (1646-1715) e Robison Crusoé (1719), de Daniel Defoe (1660-1731). Por não terem acesso à escrita e à leitura, as crianças das camadas mais populares tinham contato com uma literatura oral mantida pela tradição. A literatura, oral ou escrita, clássica ou popular, era a mesma para adultos e crianças (GREGORIN FILHO, 2009).

Em vista disso, este artigo propõe a análise de um excerto de uma obra que, podemos dizer, percorreu um caminho inverso, ou seja, foi escrita especificamente para o público infantil, mas veio a ser apreciada da mesma maneira pelos adultos: Tales from Shakespear. Designed for the use of young persons (1807) ${ }^{1}$, dos irmãos Charles e Mary Lamb, cujo conteúdo é composto por vinte peças teatrais de William Shakespeare reescritas em prosa narrativa. Apresentaremos breves considerações sobre a biografia dos autores e sobre a contextualização da obra no sistema literário infantil. Na sequência, a partir da análise comparativa entre a 
tragédia Macbeth, de William Shakespeare, e sua respectiva narrativa reescrita por Charles Lamb, investigaremos quais particularidades da reescrita poderiam caracterizá-la como um novo original.

\section{A importância da reescrita Tales from Shakespear}

Mais de quatrocentos anos transcorreram após a morte do dramaturgo inglês William Shakespeare (1564-1616), e ainda hoje seus enredos e personagens cativam as pessoas ao redor do mundo. Suas obras transcenderam o tempo e as diferentes culturas. A dimensão temporal que nos separa dele não foi suficiente para apagar o interesse ou esgotar as inúmeras possibilidades de leituras, adaptações e estudos acerca de sua obra. No decorrer dos séculos, suas peças teatrais foram reescritas para diversos meios de comunicação, como televisão, cinema, histórias em quadrinhos, videogames, entre outros, e para diferentes públicos, incluindo as crianças.

Segundo Lefevere (2000), o conceito de reescrita (rewriting) ${ }^{2}$, ou reescritura, abrange as adaptações de uma obra literária em diferentes formas para públicos distintos, podendo compreender a totalidade da obra ou apenas partes dela. A tradução corresponde a somente uma das muitas maneiras nas quais uma obra pode ser reescrita. Na definição de Lefevere, são reescritas: críticas literárias, resenhas, antologias, resumos de enredos em obras de referência, historiografia literária, biografias, transposições para outros sistemas (por exemplo: cinema, televisão, teatro), entre outros.

Para Lefevere (2007), embora as reescritas sejam percebidas como atividades auxiliares, elas são relevantes na evolução das literaturas e tornaram-se um componente fundamental na interação entre o leitor não profissional ${ }^{3}$ e a alta literatura, visto que muitas vezes ele não lê um livro tal como foi escrito pelo seu autor, porém o lê em forma de reescrita. Por meio das reescritas, os reescritores projetam imagens de uma obra literária, de um autor, de um período, que alcançam mais pessoas do que a obra propriamente dita. Para muitas pessoas que não estão expostas à literatura, as reescritas serão o original. Com isso, as reescritas participam ativamente do processo de estabelecimento da reputação de um autor e/ou de sua obra.

Tales from Shakespear é uma reescrita que adquiriu evidência própria, tornando-se conhecida em muitos países e participando da propagação do legado do dramaturgo. Segundo Richmond (2008), pesquisadora das adaptações das peças de Shakespeare para o público infantil, a obra dos irmãos Lamb atingiu uma posição de destaque que nenhuma adaptação das 
peças de Shakespeare para esse público alcançou. Logo após a época em que foi lançada tornouse um clássico. Desde então até os dias atuais, nunca deixou de ser impressa.

Para Milton (2015), a obra dos irmãos Lamb é importantíssima na divulgação de Shakespeare no mundo inteiro, e vários países conheceram suas peças por meio dessas versões simplificadas. A China pode ser citada como exemplo, pois a primeira tradução a entrar no país foi de Tales from Shakespear, em 1909, e não de uma peça teatral do poeta. De acordo com um levantamento realizado por Stanley Wells (1987), há evidências de duzentas edições da obra em inglês e traduções para quarenta idiomas.

Conforme ressalta Richmond (2008), os irmãos Lamb tiveram uma significativa participação na consolidação da literatura adulta adaptada às crianças como uma alternativa à criação de histórias específicas para elas. No entanto, paradoxalmente, a história da literatura dedica pouco espaço aos comentários sobre Tales from Shakespear.

\section{Tales from Shakespear no polissistema da literatura inglesa do início do século XIX}

Elaborada por Itamar Even-Zohar entre os anos de 1969 e 1970, a Teoria dos

130 Polissistemas foi posteriormente revisada e expandida, passando por algumas atualizações até 2011. Para o autor, a literatura está integrada no arcabouço da cultura, muitas vezes ocupando uma posição central e influente, e não pode ser considerada uma atividade isolada na sociedade. A cultura é vista como um grande sistema ${ }^{4}$ estratificado, composto por vários sistemas que se entrecruzam, funcionando como um todo estruturado. A análise do polissistema engloba as relações existentes entre esses sistemas dinâmicos, heterogêneos e históricos, porquanto estão inseridos em um determinado tempo e espaço.

Para Even-Zohar (1990), a abordagem da teoria dos polissistemas procura explicar a função de todos os tipos de escrita e pode reverter a visão de um (uni)sistema em que identificase apenas o centro - a cultura oficial que se manifesta na linguagem da norma culta, na literatura canonizada e nos padrões de comportamento da classe dominante - e concebe as periferias como extra-sistêmicas. Essa abordagem possibilita integrar à pesquisa objetos (propriedades, fenômenos) que eram antes ignorados, e essa integração passa a ser uma pré-condição para sua compreensão. Sendo assim, a linguagem da norma culta será referida levando-se em conta os contextos das variedades não padrão; a literatura infantil não será considerada um fenômeno sui generis e, portanto, deverá estar relacionada com a literatura adulta; a literatura traduzida não ficará dissociada da literatura de origem; a literatura de massa não poderá ser simplesmente descartada como não literatura. 
Ademais, na concepção de Even-Zohar (1990), a literatura abrange a totalidade das atividades envolvidas no sistema literário: produtores (escritores); consumidores (leitores); contexto (a instituição literária como um todo - editoras, críticos, universidades, órgãos governamentais, a mídia), mercado (livrarias, bibliotecas, clubes de livros, etc.), entre outros. Todos os fatores, internos e externos, fazem parte do polissistema, não apenas os textos, uma vez que a literatura não pode ser compreendida apenas como um repertório ou um agrupamento deles, apesar de serem os produtos mais evidentes do conjunto literário. Portanto, há uma relação de interdependência entre os fatores e não existe uma escala hierárquica de importância entre eles.

Podemos considerar que Tales from Shakespear teve um posicionamento singular no início do século XIX, uma vez que participava de vários sistemas. Por um lado, temos no centro do polissistema da literatura inglesa as peças de William Shakespeare - cânone então consagrado que já vinha sendo adaptado há dois séculos; por outro lado, em situação mais periférica, está a literatura infantil - um sistema ainda em formação, que sofria interferência de traduções vindas especialmente da França. E, na periferia, do mesmo modo em conexão, está o sistema da literatura traduzida, dado que Tales from Shakespear pode ser considerada uma tradução intralingual ${ }^{5}$. Nesse cenário, ainda acontecia o movimento literário posteriormente denominado Romantismo Inglês. Sendo assim, para ilustrar alguns fatores envolvidos no polissistema no qual Tales from Shakespear estava inserida, a seguir faremos brevemente algumas considerações acerca dos irmãos Lamb, da obra e de seu contexto.

\subsection{Autores: alguns fatos sobre a carreira literária dos irmãos Lamb ${ }^{6}$}

Charles Lamb (1775-1834) era poeta, ensaísta e crítico literário. Trabalhava na East India Company, onde permaneceu por trinta e três anos até sua aposentadoria. Escrevia em seu tempo livre.

Durante a época de estudos no colégio Christ's Hospital, Lamb ficara amigo de Samuel Taylor Coleridge (1772-1834), e a amizade perdurou durante toda sua vida. Por meio dele, Charles conheceu William Wordsworth (1710-1850). Coleridge e Wordsworth, considerados os precursores do Romantismo na Inglaterra com a publicação de Lyrical Ballads (1798), foram importantes na carreira de Charles Lamb, e suas crenças e aspirações influenciaram o escritor. Charles compartilhava de seus pensamentos estéticos e filosóficos sobre a poesia, adquirindo conhecimentos sobre as concepções da época, além de também exercer influência no círculo de escritores em que participava. 
A carreira de Charles Lamb começou com a publicação de quatro sonetos incluídos na obra Poems on Various Subjects, de Samuel Coleridge, em 1796. No ano seguinte, contribuiu para Poems, second edition, também dele. Continuou a escrever poesia no decorrer de sua vida, porém dedicou-se a outros gêneros literários. Em 1798, publicou o romance Rosamund Gray. Charles empenhou-se no teatro, mas suas incursões no gênero não foram bem-sucedidas. Para o público infantil, além de Tales from Shakespear, publicou The Adventures of Ulisses, em 1808, sua reescrita da obra Odisseia, de Homero. Ainda nesse ano, Charles editou uma antologia de dramas, Specimens of the English Dramatic Poets who lived about the time of Shakespeare. Suas opiniões ajudaram a consolidar sua reputação de crítico literário, e sua originalidade era reconhecida. É possível verificar isso nos textos de William Hazlitt (17781830) e Bryan Waller Procter (1787-1874), pseudônimo Barry Cornwall.

Charles Lamb também escrevia para periódicos. Em 1811, publicou o ensaio On the Tragedies of Shakespeare, considered with reference to their fitness for Stage Representation na revista The Reflector. Ele considerava, tal como muitos naquele tempo, que as peças de Shakespeare eram mais apropriadas para a leitura privada, devido à má qualidade das 132 encenações. Para ele, o verdadeiro deleite consistia em perceber as sutilezas das obras de Shakespeare em um exercício intelectual.

Em 1820, Charles foi convidado para contribuir na London Magazine. Utilizando o pseudônimo Elia, em seus ensaios ele retratou diversas pessoas de seu convívio e aspectos de sua vida. Posteriormente, os textos foram publicados em Elia (1823) e Last Essays of Elia (1833). Essas obras são consideradas o auge de sua carreira e, até hoje, ele é lembrado e notadamente reconhecido por elas.

Mary Ann Lamb (1764-1847) também era escritora. Apesar de ter tido pouca educação formal, era uma autodidata, e aprendeu latim, francês e italiano. Seu hábito de leitura desenvolveu-se na infância, quando tinha acesso à biblioteca de Samuel Salt (?-1872), empregador de seu pai. Após a publicação de Tales from Shakespear, foi convidada para escrever outros títulos para o público infantil. Em 1809, foram lançados anonimamente Mrs. Leicester's School, com histórias para meninas, e Poetry for Children, com oitenta e quatro poemas. Os livros tiveram a colaboração de Charles. Para adultos, escreveu o ensaio On Needlework em 1815.

Os irmãos Lamb levavam uma vida social ativa e costumavam ser anfitriões em sua casa, participando de encontros semanais com figuras importantes do mundo literário, intelectuais, filósofos e artistas. O círculo incluía os escritores Samuel Taylor Coleridge, 
William Wordsworth, William Godwin, William Hazlitt, Robert Southey (1774-1843) e Leigh Hunt (1784-1859). Assim, os irmãos Lamb estavam em sintonia com o movimento literário do seu tempo e faziam parte do polissistema inglês.

\subsection{Charles Lamb e os preceitos da literatura infantil inglesa}

Em meados do século XVIII e início do século XIX, sob influência das transformações sociais, políticas e culturais que ocorriam na Europa, despertava-se o interesse pelas crianças. O processo de descoberta da infância era gradual. A criança começava a ser vista como um ser com características próprias, que precisava de cuidados especiais. Até então, a criança era considerada um adulto em miniatura. A infância não era vista como um período de formação do indivíduo, e sim como uma fase que precisava ser logo atravessada para a pessoa se tornar produtiva na coletividade (COELHO, 2010).

Na época em que Tales from Shakespear foi escrita pelos irmãos Lamb, a literatura infantil encontrava-se em processo de formação e havia a preocupação com as obras oferecidas à criança. A crença de que a literatura tinha a função de reforçar ou ajudar a formar o caráter moral da criança era um pressuposto amplamente aceito no período. Era necessário contribuir para o desenvolvimento de sua mente e personalidade. $\mathrm{O}$ aspecto moralizante da literatura tinha mais relevância que o prazer proporcionado pela leitura de um texto (RICHMOND, 2008).

Porém, nessa época, acontecia o Romantismo Inglês, cujas características centrais incluíam o lirismo, a força do enredo e a importância da criatividade. As forças inventivas do indivíduo e da imaginação eram valorizadas ${ }^{7}$. Nessas circunstâncias, tínhamos os preceitos daquele momento entrando em contradição com a função moralizante da literatura infantil. Qual seria a função principal de Tales from Shakespear: predominaria o estímulo à imaginação ou à moralização?

Alguns anos antes da publicação da obra, em 23 de outubro de 1802, Charles demonstrara sua indignação contra as obras disponíveis para o público infantil. Em carta escrita a Samuel Coleridge, ele relata uma ida à livraria Newbery, a preferida pelos londrinos para livros destinados às crianças. Os irmãos haviam prometido adquirir um livro para os filhos dele, Hartley e Derwent Coleridge. A obra que queriam enviar às crianças era The History of Goody Two-Shoes (1765), escrita por Oliver Goldsmith (1728-1774). Quando publicada, ela distinguira-se de outras publicações da época, pois seu enredo era uma simples narrativa, sem conteúdo pedagógico ou religioso, que geralmente permeava os textos do período. Os irmãos a haviam lido quando pequenos e ficaram espantados quando, durante a visita à livraria, 
perceberam que o livro estava perdido em um canto com outros clássicos. Ainda na carta, Charles conta para Coleridge que obras nonsense, como as escritas por Anna Laetitia Barbauld (1743-1825) e Sarah Trimmer (1741-1810), tinham destaque. Ele demonstra sua rejeição a livros que eram delineados para ensinar e a textos moralizantes, que ressaltavam a importância de um caráter imaculado, cultivando princípios elevados e boas maneiras. Esse tipo de leitura não seria instigante para a imaginação infantil. Ele acreditava que a leitura deveria ter a função de levar a criança a sonhar. Charles pergunta a Coleridge o que teria ocorrido se a criatividade dele não tivesse sido incentivada pela leitura de contos e fábulas na infância (HITCHCOCK, 2006).

\subsection{Editor: William Godwin e sua Juvenile Library}

Em 1800, os irmãos Lamb conheceram William Godwin, cuja reputação o precedia. Suas obras Enquiry Concerning Political Justice (1793) e Things as They Are; or The Adventures of Caleb Williams (1794) tinham atraído muitos leitores, e ele era uma figura proeminente entre os círculos radicais antiaristocratas (HITCHCOCK, 2006).

As teorias sobre literatura infantil de William Godwin eram semelhantes às convicções de Charles Lamb. Considerava importante o poder da inspiração. Viúvo de Mary Wollstonecraft (1759-1797), enquanto educava suas duas filhas, ele colocava em prática suas idealizações, ensinando por meio de estímulos e exploração, inspirando o uso da criatividade, sem utilizar técnicas de memorização (HITCHCOCK, 2006).

Godwin acreditava que os métodos educacionais deveriam encorajar o descobrimento das verdades implícitas, e não impor princípios ou práticas que as obscureceriam. Ele ia em direção contrária aos escritores do período, pois julgava ser necessário desenvolver a autonomia moral das crianças. A maioria conservadora tinha a crença de que a criança era inapta para tomar decisões morais de maneira independente. Godwin queria promover justamente o que os escritores queriam evitar: a possibilidade de a criança formar seus próprios princípios (CLEMIT, 2009).

Em dezembro de 1801, Godwin casou-se com Mary Jane Clairmont (1766-1841), tradutora, que tinha valiosa experiência comercial. Godwin era um homem idealista e visionário, que enxergava o aumento da produção de livros infantis e vislumbrava o potencial do mercado consumidor. Encorajado pela mulher, iniciou um empreendimento de publicações, a Juvenile Library, em 1805, esperando transformar em um meio de subsistência o seu interesse por uma educação democrática e sua experiência em criar as filhas. O catálogo da editora 
chegou a ter sessenta títulos, cujos preços eram acessíveis aos clientes das classes com menor poder aquisitivo, dado que Godwin visava popularizar a leitura (HITCHCOCK, 2006).

Em 1806, o casal Godwin convidou Mary Lamb para escrever um livro com versões em prosa narrativa das peças de Shakespeare para o público infantil. É interessante notar que Mary foi contratada, e não o irmão ${ }^{8}$. Em 10 de maio de 1806, em carta ao amigo Thomas Manning (1772-1840), Charles descreve o trabalho no qual Mary estava engajada: ela já reescrevera seis comédias, e ele dizia que a estava ajudando. Tinha reescrito Othello e Macbeth, e ficara responsável pelas tragédias. Com isso, pode-se supor que ele considerava que o projeto pertencia à irmã (HITCHCOCK, 2006).

Em cartas entre Charles Lamb e William Godwin não há registros sobre Tales from Shakespear. Não existem evidências de conflitos entre o editor e os autores durante sua composição. Depois, enquanto Charles reescrevia The Adventures of Ulisses, ambos discordam sobre a adequação de algumas cenas ao público infantil. Charles não assentia com o pedido de Godwin para amenizar seu enredo, pois acreditava que elementos aterrorizantes eram indicados para estimular a fantasia das crianças (HITCHCOCK, 2006).

\subsection{A obra: alguns dados sobre Tales from Shakespear}

Tales from Shakespear. Designed for the use of young persons é composta por vinte peças teatrais reescritas em prosa, para adequá-las ao público infantil. A primeira edição tinha 520 páginas, em dois volumes. Trazia as tragédias de Shakespeare reescritas por Charles Lamb: King Lear; Macbeth; Timon of Athens; Romeo and Juliet; Hamlet, Prince of Denmark; Othello. E as comédias do referido autor reescritas por Mary Lamb: The Tempest; A Midsummer Night's Dream; The Winter's Tale; Much Ado About Nothing; As You Like It; The Two Gentlemen of Verona; The Merchant of Venice; Cymberline; All's Well That Ends Well; The Taming of The Shrew; The Comedy of Errors; Measure for Measure; Twelfth Night, or What You Will; Pericles, Prince of Tyre.

Anteriormente à publicação da versão completa com as vinte narrativas acima mencionadas, foram impressas edições individuais de oito narrativas em formato chapbook, que era um pequeno folheto de baixo custo, muito difundido naquele tempo porquanto era uma alternativa para a classe alfabetizada sem recursos financeiros. Embora sua origem tivesse foco no público adulto, os chapbooks ficaram populares entre as crianças. Com a obra Tales from Shakespear, como já mencionamos, ocorreu o oposto, visto que se tornou um clássico para adultos, não obstante seu foco ser o público infantil (RICHMOND, 2008). 
O prefácio traz que os autores gostariam que a obra fosse uma introdução às peças de William Shakespeare para os jovens leitores, especialmente para as young ladies, meninas que teriam acesso aos livros dos pais apenas em uma idade mais avançada que os meninos. $\mathrm{O}$ propósito deles era estimular a posterior leitura das peças integrais (LAMB, 2007).

Para ilustrar a primeira edição, os Godwin contrataram William Mulready (1786-1863). Teve também a colaboração de William Blake (1757-1827), que ajudou na gravação das ilustrações. Acredita-se que alguns desenhos eram seus, como a imagem da capa, mas seu nome não aparecia na obra (HITCHCOCK, 2006).

Apesar de serem executadas por renomados artistas, as ilustrações não agradaram a Charles Lamb. Em carta a William Wordsworth em 29 de janeiro de 1807, ele culpa Mary Jane Godwin pelos erros. Algumas imagens traziam detalhes conscientemente omitidos pelos irmãos nas narrativas. A segunda edição de Tales from Shakespear, não se sabe se devido às objeções de Charles ou por questões de custo, não continha mais as ilustrações, apenas a imagem do busto de Shakespeare (HITCHCOCK, 2006).

A recepção de Tales from Shakespear, para Wells (1987), foi sem grande entusiasmo, 136 com uma exceção, a crítica veiculada no Critical Review, em maio de 1807, que colocava a obra no contexto do debate sobre literatura infantil. Nessa avaliação, o livro era apontado como uma das melhores opções para atrair a atenção das crianças porque estimulava a imaginação sem didatismo. Além desta, houve seis críticas anônimas em periódicos, muito centradas no propósito moral.

A obra obteve sucesso moderado enquanto os irmãos viviam - foram onze edições no período. Até o ano da morte de Charles, em 1834, foram impressas seis. Quando Mary morreu, em 1847, haviam saído mais cinco edições. Depois disso, sua popularidade foi aumentando cada vez mais.

Desde que Tales from Shakespear chegou ao Brasil, no início do século XX, foi traduzida para a língua portuguesa por diversos tradutores. Em uma busca na base de dados da Fundação Biblioteca Nacional, verificamos que alguns deles foram: Telesploro Prata (1937), Mario Quintana (1943), Octavio Mendes Cajado (1954), Péricles Eugênio da Silva Ramos (1959), Paulo Mendes Campos (1970), Oliveira Ribeiro Neto (1970), Floriano Tescarolo (1997), Vera Lopes da Silva (1997), Sérgio Godinho de Oliveira (2002), Marcos Bagno (2003), Marcos Maffei (2003) e Nelson Albissú (2012). Vale ressaltar que nem todos traduziram todas as narrativas. Além disso, muitas obras não têm o registro bibliográfico completo na base de dados, não citando o nome do tradutor ${ }^{9}$. 


\section{Análise: Macbeth, por Charles Lamb}

Podemos presumir que os irmãos Lamb ponderavam acerca da problemática que envolvia o processo de reescrita das peças teatrais de William Shakespeare, uma vez que abordam o assunto em seu prefácio, onde declaram que tinham em mente as aptidões do seu público enquanto escreviam, além de apontarem que determinados temas do mundo adulto que não seriam adequados às crianças tornavam árdua a tarefa (LAMB, 2007).

Naquela época, as peças de Shakespeare eram consideradas difíceis e inapropriadas não apenas para crianças, mas também para adultos (RICHMOND, 2008). Adaptá-las em modo de narrativa para o público infantil envolvia um certo nível de complexidade devido a diversos motivos, que serão apresentados a seguir.

Primeiramente, o enredo da peça teatral Macbeth traz elementos que podem ser considerados não muito apropriados às crianças. A história retrata aspectos da natureza humana, expondo complexas situações e características do turbulento mundo dos adultos, os quais as crianças supostamente ainda não conhecem. São abordados temas como poder, ambição, traição e culpa, além de incluir assassinatos, forças sobrenaturais e referências sexuais. Apesar disso, em sua reescrita, Charles Lamb reconta o argumento principal da peça, afinal, é o enredo dela, e apaga somente qualquer ambiguidade que pudesse remeter a sexo. $\mathrm{O}$ autor mantém a trama e os temas do texto de Shakespeare.

Outras questões a serem consideradas na reescrita de Lamb compreendem o idioma, a linguagem e a estrutura poética da peça teatral. Macbeth, de Shakespeare, foi escrita em Early Modern English, o inglês que era falado no fim do século XVI e início do XVII, ou seja, uma versão da língua inglesa que apresenta um léxico mais arcaico e algumas características diversas às padronizações do inglês de duzentos anos depois, da época de Charles Lamb, o Modern English. No entanto, na narrativa, podemos notar que o autor optou por utilizar trechos de Shakespeare contendo os pronomes thou, thee e thy, embora estivessem em desuso na linguagem padrão de seu tempo.

A linguagem utilizada por Shakespeare é intencionalmente trabalhada, rica em metáforas inusitadas e trocadilhos, em um trabalho paranomástico em que são explorados os aspectos sonoros e semânticos das palavras. A maior parte de Macbeth está em versos sem rima, denominados versos brancos (blank verse), e com uma métrica regular, que segue o ritmo chamado pentâmetro iâmbico (iambic pentameter) - verso de cinco pés, sendo que cada pé é composto de uma sílaba tônica e uma átona. Geralmente, as falas dos personagens secundários 
ou pertencentes às classes mais pobres são expressas em forma de prosa, mas os nobres aparecem conversando desta maneira em alguns momentos.

Ao ler Macbeth de Charles Lamb, podemos constatar que algumas passagens não são paráfrases de Lamb, e sim citações editadas, ou seja, alguns excertos que ele utiliza na narrativa são quase reproduções palavra por palavra da peça, com variações mínimas, como se ele repetisse um fragmento que sabia de memória. Percebe-se claramente que as palavras de Shakespeare são empregadas sempre que possível, como o autor informa em seu prefácio, e a narrativa traz trechos em versos brancos inalterados. Lamb também emprega metáforas utilizadas por Shakespeare, por vezes explicitando seus significados, possivelmente em função das supostas aptidões do público leitor.

Macbeth é conduzida por um narrador em terceira pessoa, que se posiciona fora dos fatos, com um ponto de vista relativamente imparcial. Para direcionar a história, Lamb opta por não seguir exatamente a cronologia da peça, visto que é necessário narrar uma sequência de eventos, entretanto, a sucessão dos episódios segue semelhante à peça de Shakespeare. O autor utiliza o discurso indireto com algumas inserções do discurso direto.

Lamb condensa o texto da peça teatral em função do limite de texto delimitado por seu editor, em torno de cinco mil palavras (NEWMAN, 2008). A narrativa tem trinta e sete parágrafos relativamente extensos. $\mathrm{O}$ autor prioriza os acontecimentos principais do enredo e exclui as tramas secundárias, sintetizando ou suprimindo trechos e detalhes referentes à história ou aos personagens. Por outro lado, Lamb clarifica algumas passagens, incluindo a menção a um fato histórico em relação à sucessão dos reis da Escócia a partir do filho de Banquo, que não há na peça teatral. As intervenções significativas encontradas na história reescrita por Lamb foram em relação ao casal Macbeth.

Em sua narrativa, Lamb apresenta o herói ${ }^{10}$ Macbeth com as principais características do personagem de Shakespeare: um guerreiro que se destaca por sua força e bravura, cuja fama no campo de batalha dá-lhe grande honra perante o Rei Duncan. Em contrapartida, ele já apresenta lady Macbeth como sendo má e ambiciosa. Interessante que, para descrevê-la, Lamb utiliza uma metáfora que fora empregada por Shakespeare na fala de lady Macbeth para aconselhar seu marido a ser dissimulado. Na peça, a personagem compara o rosto de Macbeth a um livro em que os outros podem ler suas intenções e preocupações, por isso o aconselha a esconder seus sentimentos. Ela diz que ele deve se parecer com uma flor inocente, entretanto ser a serpente por baixo dessa flor. Ao reescrever o texto, Lamb utiliza a metáfora para 
caracterizar lady Macbeth, dizendo que ela poderia parecer a flor inocente, enquanto era de fato a serpente embaixo dela:

Quadro 1 - Macbeth, por William Shakespeare e Charles Lamb

\begin{tabular}{|l|l|}
\hline SHAKESPEARE (1.5.62-66) & LAMB, 2007, p. 125 \\
LADY MACBETH & {$[\ldots]$ lady Macbeth [...] could look like the innocent } \\
{$[\ldots]$} & flower, while she was indeed the serpent under it. $^{12}$ \\
Your face, my thane, is as a book, where men & \\
May read strange matters; to beguile the time, \\
Look like the time, bear welcome in your eye, \\
$\begin{array}{l}\text { Your hand, your tongue; look like the innocent } \\
\text { flower, } \\
\text { But be the serpent under't. }{ }^{11}\end{array}$ & \\
\hline
\end{tabular}

Elaboração: Flavia Gonçalves

Na peça teatral de Shakespeare, há indícios de que a ideia inicial do assassinato do Rei Duncan foi de Macbeth. Ao ter sua ambição atiçada, já lhe ocorrem os primeiros pensamentos de cometer regicídio. Ainda que a ideia tenha sido dele, lady Macbeth participa ativamente do assassínio, sendo responsável por convencer o marido, ajudando-o a concretizar os desígnios dos dois.

Em relação a isso, o enredo de Lamb traz modificações. Em sua narrativa, lady Macbeth é apresentada como a principal mentora do crime, e sua participação no assassinato é expandida. Ela acorda no meio da noite para planejar o assassínio e tenta matar Duncan, mas não consegue porque ele a lembrava seu pai. O planejamento na madrugada e a tentativa de lady Macbeth cometer o assassinato não existem na peça teatral.

Quadro 2-Macbeth, por Charles Lamb

Now was the middle of night, [...] This was the time when lady Macbeth waked to plot the murder of the king. [...] So with her own hands armed with a dagger, she approached the king's bed; [...] there was something in his face, as he slept, which resembled her own father; and she had not the courage to proceed. ${ }^{13}$

Fonte: Lamb (2007, p. 125)

O terceiro ato da peça de Shakespeare marca o início do reinado de Macbeth. A primeira cena traz Macbeth conversando com dois assassinos para matarem o general Banquo e seu filho Fleance porque ele percebe que está vulnerável e não deseja que a profecia das bruxas, que prenunciava uma linhagem de reis descendente de Banquo, transforme-se em realidade. Macbeth teme Banquo. O declínio do herói Macbeth teve início quando ele assassinou o rei. Passou de uma situação de felicidade para infortúnio por uma falha de seu caráter. Agora, neste 
ponto da peça, ele não precisa mais de sua esposa para agir. Macbeth trama e ordena a morte de Banquo e Fleance, não expondo claramente os seus planos para lady Macbeth.

Em sua reescrita dessas passagens, Lamb condensa as informações, excluindo o medo que Macbeth tem dele. Porém, diferentemente do que fora escrito por Shakespeare, Lamb relata que a decisão de matar Banquo e Fleance é tomada em conjunto por Macbeth e lady Macbeth.

Quadro 3-Macbeth, por Charles Lamb

[...] Macbeth and his queen could not forget the prophecy of the weird sisters [...] that they determined to put to death both Banquo and his son $[\ldots]^{14}$

Fonte: Lamb (2007, p. 128)

Ao efetuar uma leitura e análise da primeira parte da narrativa de Charles Lamb, fica a impressão que a principal vilã da história é lady Macbeth, e o marido é apenas um coadjuvante, acompanhando-a, meramente, em suas maldades. No texto de Lamb, o lado perverso da personalidade de Macbeth é somente destacado após as predições dos espíritos conjurados pelas bruxas, quando ele é rei.

Em nossa hipótese, o fato de Lamb amenizar as intenções maléficas de Macbeth e expandir a participação de lady Macbeth poderia revelar que, de maneira implícita, em sua reescrita a mulher seria a causa da derrota do herói. Por isso, Lamb poderia estar justificando as maldades de Macbeth como sendo motivadas por influências externas.

Poderíamos também presumir que as modificações de Lamb em sua narrativa resultaram em um herói Macbeth mais em consonância com o herói da tragédia grega. As modificações de Lamb teriam deixado Macbeth mais fiel ao padrão do herói clássico que, apesar de ser bom, comete erros por influências externas e não escapa de seu destino. Diferentemente da tragédia grega, em Shakespeare existe o livre-arbítrio. Segundo Bradley (2009, p. 5-9), o herói se destaca por suas qualidades, porém é conduzido à morte por aspectos intensos de sua vida, uma catástrofe excepcional. As calamidades não acontecem simplesmente ou são enviadas, elas decorrem, primordialmente, de atos humanos. O herói da tragédia Shakespeariana faz escolhas e uma falha de seu caráter o leva à queda.

\section{Considerações finais}

Este trabalho teve como propósito analisar algumas particularidades da narrativa Macbeth, por Charles Lamb, para o público infantil. Consideramos Tales from Shakespear uma reescrita das peças teatrais de William Shakespeare, uma vez que ela compreende, segundo 
definido por Lefevere (2000), a adaptação de uma obra literária em uma forma diferente, no caso narrativa, para um público distinto, as crianças do início do século XIX.

Inicialmente, foram feitas considerações sobre a importância de Tales from Shakespear e seu posicionamento no polissistema da literatura inglesa daquele tempo. Apresentamos brevemente a biografia dos autores, do editor e seus preceitos acerca da literatura infantil. $\mathrm{Na}$ sequência, mostramos alguns dados sobre a obra. Depois, apresentamos as características da fonte textual que podem ser consideradas questões complexas em uma adaptação para crianças. Então, expusemos algumas peculiaridades da narrativa a partir de um cotejo com o texto dramático.

A análise comparativa demonstrou que a narrativa de Charles Lamb traz os principais acontecimentos da peça teatral de William Shakespeare, embora seja um texto que tenha passado por uma condensação. Os temas da peça, ainda que possam ser considerados inadequados para as crianças, foram abordados na narrativa, excetuando-se apenas as referências sexuais. Lamb atualizou o idioma da peça para o inglês moderno, contudo usou pronomes arcaicos na narrativa. Ele manteve alguns trechos em versos brancos e reescreveu algumas passagens utilizando as mesmas palavras empregadas por Shakespeare. Para contar a história, foi inserido um narrador em terceira pessoa. Lamb recorreu ao discurso indireto, fazendo algumas inserções em discurso direto.

No enredo da narrativa, lady Macbeth foi apresentada como a principal mentora do crime, e sua participação no assassinato foi expandida. As intenções maléficas de Macbeth foram amenizadas. As modificações de Lamb deixaram Macbeth mais fiel ao padrão do herói clássico que, apesar de ser bom, comete erros por influências externas e não escapa de seu destino. Diferentemente da tragédia grega, o herói da tragédia Shakespeariana faz escolhas e uma falha de seu caráter o leva à queda.

Em nossa análise, foi possível verificar que, apesar de trazer algumas características próprias, a narrativa de Charles Lamb está em consonância com a peça teatral de Shakespeare. No entanto, podemos conjecturar que um leitor que fizesse a leitura da narrativa, porém nunca procurasse a peça de Shakespeare, poderia ter uma determinada imagem de um trecho ou personagem que não corresponderia ao que fora escrito pelo dramaturgo. Por exemplo, pensaria que lady Macbeth tentou assassinar o rei, fato que acontece apenas na narrativa reescrita por Lamb, e não na peça teatral Macbeth. Os leitores que tivessem tido acesso apenas às narrativas dos irmãos Lamb poderiam considerá-las como as verdadeiras histórias de Shakespeare, isto é, as narrativas seriam o original para eles. 


\section{REFERÊNCIAS BIBLIOGRÁFICAS}

ARISTÓTELES. Poética. Tradução, introdução e notas: Paulo Pinheiro. 2. ed. São Paulo: Editora 34, 2017.

BRADley, A. C. A Tragédia Shakespeariana: Hamlet, Otelo, Rei Lear, Macbeth. Traduzido por: Alexandre Feitosa Rosas. São Paulo: Martins Fontes, 2009.

BURGESS, Anthony. A Literatura Inglesa. Traduzido por: Duda Machado. 2. ed. São Paulo: Ática: 2008.

CLEMIT, Pamela. William Godwin's Juvenile Library, The Charles Lamb Bulletin, London, 2009, New Series n. 194, p. 90-99. Disponível em: www.charleslambsociety.com Acesso em: 12 fev. 2019.

COELHO, Nelly Novaes. Panorama Histórico da Literatura Infantil/Juvenil. 5. ed. São Paulo: Amarilys, 2010.

COELHO, Nelly Novaes. Literatura Infantil: teoria, análise, didática. 7. ed. São Paulo: Moderna, 2011.

EVEN-ZOHAR, Itamar. Polysystem Studies, Poetics Today: Internacional Journal for Theory and Analysis of Literature and Communication, Durham, v. 11, n. 1, p. 1-268, 1990.

FUNDAÇÃO BIBLIOTECA NACIONAL. Disponível em: www.bn.br Acesso em: 12 fev. 2019.

GREGORIN FILHO, José Nicolau. Concepção de Infância e Literatura Infantil, Linha D'Água, 2009, São Paulo, n. 22, p. 129-135. Disponível em: https://www.revistas.usp.br/linhadagua/article/view/37329 Acesso em: 12 fev. 2019.

HITCHCOCK, Susan Tyler. Mad Mary Lamb: Lunacy and Murder in Literary London. New York: W.W. Norton \& Company, 2006.

JAKOBSON, Roman. Linguística e Comunicação. 22. ed. Traduzido por: Izidoro Blikstein e José Paulo Paes. 22 ed. São Paulo: Cultrix, 2010.

LAMB, Charles; LAMB, Mary. Tales from Shakespeare. London: Penguin Classics, 2007.

LEFEVERE, André. Mother Courage's Cucumbers: text, system and refraction in a theory of literature. In: VENUTTI, Lawrence (org.). Translation Studies Reader. London; New York: Routledge, 2000. p. 233-249.

LEFEVERE, André. Tradução, Reescrita e Manipulação da Fama Literária. Traduzido por: Claudia Matos Seligmann. Bauru: Edusc, 2007.

MILTON, John. Tradução \& Adaptação. In: AMORIM, Lauro Maia, RODRIGUES, Cristina C.; STUPIELLO, Érika N. A. (org.). Tradução \&: Perspectivas Teóricas e Práticas. São Paulo: Unesp, 2015. p. 17-43. 
NEWMAN, Hilary. The Lambs' "Tales from Shakespear" and Shakespeare's Plays, The Charles Lamb Bulletin, London, 2008, New Series n. 141, p. 20-28. Disponível em: www.charleslambsociety.com. Acesso em: 12 fev. 2019.

RICHMOND, Velma Bourgeois. Shakespeare as Children's Literature: Edwardian Retellings in Words and Pictures. Jefferson; London: Mcfarland, 2008.

SHAKESPEARE, William. Macbeth. CLARK, Sandra; MASON, Pamela (ed.). London: Bloomsbury, 2017. (The Arden Shakespeare Tragedies: Third Series).

WARNER, Marina. Introduction. In: LAMB, Charles; LAMB, Mary. Tales from Shakespeare. London: Penguin Classics, 2007. p. vii-Xxviii.

WELLS, Stanley. Tales from Shakespeare, British Academy Shakespeare Lectures: 19652003, 1987, p. 125-152. Disponível em: https://www.britac.ac.uk/shakespeare-lectures Acesso em: 12 fev. 2019.

\footnotetext{
* Flavia GONÇALVES - Mestranda em Estudos da Tradução pela Universidade de São Paulo (USP), bolsista CAPES-DS. Bacharel em Tradução e Interpretação (2015) pela Universidade Católica de Santos (Unisantos). São Paulo, São Paulo, Brasil.

O presente trabalho foi realizado com apoio da Coordenação de Aperfeiçoamento de Pessoal de Nível Superior Brasil (CAPES) - Código de Financiamento 001.

Currículo acadêmico: http://lattes.cnpq.br/0522621085673889

ORCID: https://orcid.org/0000-0002-2809-1974

E-mail: flaviawgoncalves@uol.com.br

${ }^{1}$ Doravante Tales from Shakespear.

${ }^{2}$ Em seu artigo Mother Courage's Cucumbers: text, system and refraction in a theory of literature (1982), Lefevere utilizava o termo refração (refraction). Em publicações posteriores, ele passa a adotar o vocábulo reescrita (rewriting).
}

${ }^{3}$ Segundo Lefevere (2007), leitores profissionais são aqueles que têm alguma conexão com a literatura, que leem de maneira profissional, tais como críticos, professores e estudantes. Leitores não profissionais seriam as demais pessoas, ou seja, a maioria dos leitores nas sociedades contemporâneas. Não se deve julgar o termo não profissional como pejorativo, uma vez que o teórico ressalta que a distinção entre leitores profissionais e leitores não profissionais não implica qualquer julgamento de valor.

${ }^{4}$ Even-Zohar utiliza o termo sistema a partir das concepções do Funcionalismo Dinâmico: a rede de relações que pode admitir hipótese para dado conjunto de supostos observáveis [ocorrências/fenômenos] - the network of relations that can be hypothesized for a set of assumed observables ['occurrences/'phenomena'] (1990, p. 27).

${ }^{5}$ Para Roman Jakobson, em seu ensaio Aspectos Linguísticos da Tradução, publicado em 1963, a tradução intralingual é a substituição de signos linguísticos por outros signos do mesmo código linguístico, ou seja, da mesma língua. A tradução interlingual ocorre quando há a substituição de signos linguísticos de uma língua por signos linguísticos de outra língua. A tradução intersemiótica abrange as substituições parciais ou totais de signos linguísticos por signos de outros códigos, como um romance que fosse adaptado ao cinema.

${ }^{6}$ A leitura sobre a biografia dos irmãos Lamb foi realizada em diversas fontes durante o desenvolvimento do projeto. Com o intuito de evitar a repetição de referências, as informações referentes à vida deles foram coletadas em Mad Mary Lamb: lunacy and murder in literary London, de Susan Tyler Hitchcock, 2006.

${ }^{7}$ Romantismo Inglês é uma designação tardia para o movimento literário no qual participavam alguns poetas que expressavam questões que refletiam o tempo em que viviam, ou seja, a época das transformações sociais provocadas pela Revolução Industrial (1760-1820/40) e das ideias revolucionárias da Revolução Francesa (17891799). A publicação de Lyrical Ballads, de William Wordsworth (1770-1850) e Samuel Taylor Coleridge (17721834), em 1798, é considerada o marco do início do Romantismo Inglês. O prefácio da obra trazia os princípios 
em que a composição da poesia deveria estar baseada. Segundo as concepções de Wordsworth, a poesia era uma vocação, e o poeta era um homem que dava vida ao cotidiano. A linguagem da poesia precisava ser a linguagem das pessoas comuns, das pessoas do campo. Era necessário exaltar a natureza, pois ela significava mais do que todos os sistemas. Wordsworth desejava um retorno ao simples, ao coração humano e à imaginação. Para ele, as crianças eram as verdadeiras depositárias da virtude e da sabedoria. Por outro lado, diferentemente de Wordsworth, Coleridge acreditava na introdução do sobrenatural na poesia, com um regresso ao mundo mágico do passado, cheio de mistério e imaginação. William Wordsworth e Samuel Taylor Coleridge, bem como William Blake (17571827), pertencem à primeira geração do movimento literário. A segunda fase do Romantismo Inglês inclui nomes como Lord Byron (1788-1824), Percy Bysshe Shelley (1792-1822) e John Keats (1795-1821), entre outros (BURGESS, 2008).

${ }^{8}$ Nas primeiras edições, apenas o nome de Charles Lamb aparecia como autor da obra, e Mary Lamb não era citada como coautora. Seu nome foi incluído alguns anos depois, em 1838, na sétima edição (WARNER, 2007).

${ }^{9}$ Para um resultado mais completo, faz-se necessária uma pesquisa em outras fontes, podendo ser aprofundada no futuro. Não foram considerados os tradutores de outros países lusófonos.

${ }^{10}$ A tragédia clássica, segundo conceitos do filósofo grego Aristóteles (384-322 a.C.), suscita compaixão e pavor, realizando a catarse das emoções dos espectadores por meio de ações dramatizadas por atores. Para que a situação de tragédia seja configurada, a construção do enredo deve oferecer uma mudança na situação do herói, da felicidade para o infortúnio. Para tal, o herói deve ser apresentado como sendo melhor que os homens comuns, possuir qualidades admiráveis que se destacam. O estado inicial do herói trágico é de eminência, que se distingue por suas qualidades físicas, sociais e espirituais. Ele não é mau nem perverso. Porém, o herói cai no infortúnio em consequência de algum erro cometido, por algum erro de julgamento ou influência externa, não por vício e depravação (ARISTÓTELES, 2017).

${ }^{11}$ Seu rosto, meu thane, é um livro no qual os homens

Podem ler estranhos assuntos; para enganar o tempo,

144 Apresenta-te de acordo com a ocasião; mostra as boas-vindas em teu olhar,

Em suas mãos, em sua língua; pareça a flor inocente,

Mas seja a serpente sob esse disfarce. (SHAKESPEARE, Ato I: cena 5, 62-66 - tradução nossa)

${ }^{12}$ lady Macbeth [...] poderia parecer a flor inocente, enquanto era de fato a serpente embaixo dela (LAMB, 2007, p. 125 , tradução nossa).

${ }^{13}$ Agora era o meio da noite, [...] Foi nesse momento que lady Macbeth acordou para planejar o assassinato do rei. [...] Assim, com suas próprias mãos armadas com uma adaga, ela se aproximou da cama do rei; [...] havia algo em seu rosto, enquanto ele dormia, que lembrava o seu pai; e ela não teve coragem de prosseguir (LAMB, 2007, p. 125 , tradução nossa).

${ }^{14}$ Macbeth e sua rainha não conseguiam esquecer a profecia das estranhas irmãs [...] que decidiram matar Banquo e seu filho (LAMB, 2007, p. 128, tradução nossa). 